\title{
FABRIC ANALYSIS OF A DEFORMED VEIN
}

SIR,-J. T. Nettle (Geol. Mag., 1964, 101, 220-7) describes an interesting rock in his recent paper in your magazine. I have been working on these Llangollen veins (spar bands) for several years and although I hope to prepare an account of them in the near future, there are three matters arising directly from his paper on which it seems useful to take issue now.

Firstly, Nettle (p. 221) seems to be suggesting that the veins were folded in an episode of deformation later than that in which the folds and cleavage of the Llangollen slates were produced. He seems to reach his conclusion for two main reasons. The first concerns the variation from the regional attitude of the cleavage of the slates immediately adjacent to the folded veins (p. 220). This variation, however, is of the kind very common in folded sequences of more and less competent material and the Llangollen slates provide exactly the same phenomenon on the same scale where thin sandy layers are folded concentrically in the more pelitic slate. Here, of course, the layered structure was folded in the cleavage-forming deformation and this I suggest is true of the veins also. His second reason for arguing that the veins are younger than cleavage stems from the presence together of similar folds in the slates and concentric folds in the veins. However, as described above, sandy layers in the slate also are folded concentrically and the similar folds in the slates which he notes are of large size, and not the hand specimen dimensions of the folds of veins and sandy layers. Thus the presence together of concentric folds in the veins and similar folds in the slates is no argument for the slight (p. 220) amount of movement which he proposes produced the concentric folds ; a movement which occurred, according to Nettle (p. 221), after the cessation of the deformation which produced the large similar folds of the slates and the cleavage. In any case folds on all scales have the same axis orientation and general axial plane attitude, more or less parallel to the cleavage of the slates, and the folds of the veins exactly match in style the small folds of bedding in the adjacent slate. Furthermore, he proposes that the veins formed along "lines of weakness afforded by the bedding planes" (p. 220) but it is not clear whether he is suggesting they formed before or after cleavage production. If the former is the case why were they not folded when cleavage was produced and if the latter, how is it that bedding then offered for their development a sufficient "line of weakness" in the well-cleaved slate?

Secondly, Nettle (p. 223) suggests that the fabric of the veins developed as a result of a "compression parallel to the $c$ axis of the fabric or relative extension parallel to the $a$ axis "which accompanied the formation of the so-called drag folds of the veins; a movement which on p. 220 he defines as slight. As he correctly describes the fabric, the calcite crystals of the veins have a very pronounced $c$-axis preferred orientation perpendicular to the vein wall and to the disc-like calcite crystals. Unlike Nettle I find it difficult to reconcile the development of this very pronounced crystallographic $c$-axis and dimensional orientation with the stresses necessary to produce the drag folds of the veins. There is good experimental evidence (for example in Mem. 79 of the Geol. Soc. Amer., pp. 87-94) that considerable compression or elongation is necessary to produce by deformation alone fabrics as marked as these of the Llangollen veins. May I suggest that unlike Nettle (p. 225) one should not dismiss recrystallization as a probable agent in the development of the fabric?

Finally, may I disagree with his description of the local extent of the vein fabric-forming conditions (see Nettle, p. 223) for such veins are found, as Wills and Smith noted (see the Wrexham Memoir, 1926) over some miles of the Llangollen area, although through a limited succession of rocks, and also occur in a similar sedimentary facies in Ribblesdale at what may well be the same stratigraphic level.

Department of Geology,

R. NichOLSON.

THE UNIVERSITY, MANCHESTER, 13.

14th September, 1964. 